\title{
Weathering Mechanism of Soft Rock under the Combined Effect of Pressure and Temperature
}

\author{
Wang Lin-feng ${ }^{1, *}$, Sun Hao ${ }^{1}$, Yao Chang-yin ${ }^{1}$, Jin Hong-hua ${ }^{1}$, Tang Hong-mei ${ }^{1}$, Wang Zong-jian ${ }^{1,2}$ \\ ${ }^{1}$ School of River \& Ocean Engineering, Chongqing Jiaotong University, Chongqing 400074, China \\ ${ }^{2}$ Maeda Kohsen Co. Ltd., Fukui 9190422, Japan
}

Received 7 June 2017; Accepted 26 January 2018

\begin{abstract}
Cause analysis and depth calculation of rock cell can significantly help demonstrate the weathering mechanism of the soft rock of the rock cell. However, the current methods of analyzing weathering mechanism attach little importance to the mechanical environment of rock. Damage mechanics typically involves the calculation of a damage factor. To explore the weathering mechanism of soft rock at the lower part of gently inclining rock slope, this study based on the calculation method of a damage factor in damage mechanics, proposed a calculation formula for the damage factor of soft rock under the combined effect of pressure and temperature and the method for fatigue rupture. Then, taking the mudstone of a single rock cell in Hongyan Mountain of Jiangjin in China as an example, the calculation formula and method for soft rock were used to analyze its weathering mechanism. The analytical parameters included weathering rate, damage, and fatigue rupture of soft rock. Results show that the maximum influencing depth of temperature on soft rock is approximately $1.00-1.20 \mathrm{~m}$, and the weathering rate of the soft rock is faster at the beginning of temperature fatigue loading. Weathering rate slows down with the fatigue number increasing. At the lower-level temperature difference, the weathering process of soft rock accelerates when the rock shifts from low to high temperature. However, when the soft rock is in large temperature difference, the weathering process accelerates at the relatively lower rate. The damage of the soft rock is linearly related to the pressure from the upper hard rock. Conclusions of this study provide a theoretical basis for the prevention and treatment of collapsed hazards of gently inclining rock slope.
\end{abstract}

Keywords: Soft rock, Weathering, Gently inclining rock slope, Temperature, Pressure, Damage

\section{Introduction}

Gently inclining rock slope is rock slope with inclination angles of less than $10^{\circ}$. Collapsed rock on gently inclining rock slope is induced by the differential weathering of soft and hard rock. Soft rock at the lower part of gently inclining rock slope has faster weathering rate than the upper hard rock; then, rock cell is formed outside the soft rock, causing the upper hard rock to vacant and eventually collapse [1]. The rock cell on weathered soft rock is starter of the rock collapse at gently inclining rock slope. Thus, the rock cell must be treated effectively to avoid collapse-related disasters Determining the weathering mechanism of soft rock is necessary for the proper treatment of rock cell. The weathering of soft rock at the lower part of gently inclining rock slope is actually produced under the combined effect of pressure and variations in diurnal temperature difference of upper hard rock.

Rock weathering can be divided into three types: physical, chemical, and biological. The weathering of general rock is accompanied by changes in mineral composition (i.e., chemical weathering) [2-3]. Thus, most existing researches have mainly adopted field investigation, monitoring, laboratory test, numerical simulation, and similar methods that identify the changing processes of the mineral composition, cement dissolution, and strength

*E-mail address: wanglinfeng715@163.com

ISSN: $1791-2377$ @ 2018 Eastern Macedonia and Thrace Institute of Technology. All rights reserved. doi:10.25103/jestr. 111.20 attenuation of weathering rock [3-6]. The positioning of soft rock within rock cell is typified by a relatively dry environment (i.e., free of water, chemical fluids, and plants), and thus, chemical and biological weathering are unlikely. On the basis of field investigations, the weathering of soft rock within a rock cell is mainly caused by the joint action of upper rock fracturing and diurnal temperature difference [4], which suggests that soft rock within rock cell undergoes weathering mechanism that differ from those of common rock. Hence, the weathering mechanism of common rock has reported in previous work cannot fully explain the weathering mechanism of soft rock within rock cell at the lower part of gently inclining rock slope.

\section{State of the art}

The massive destructiveness and abruptness of crag collapse disasters have prompted foreign and domestic scholars to conduct studies on the topic. However, these studies have mainly focused on the post-collapse movement locus of rockfall, passive protections, and failure mechanism of upper hard rock. Rammer et al. [7] analyzed the effects of rockfall movement and the intercept capacity of trees on the slope. Lee et al. [8], by taking a typical layered rock slope in Korea as an example, studied the stability of a slope, analyzed the strength of structural surfaces and their combination, and verified the rationality of the study method with Universal Distinct Element Code software programming. Zhang et al. [9] analyzed the evolution process of jointed rock slope 
using fracture mechanics and the strength reduction method. $\mathrm{Xu}$ et al. [10-13] analyzed the stability of rock slope using a finite element software and by referring to damage mechanics. Shukla et al. [14] analyzed the influences of earthquake, crevice water, and overloading on top slope using calculation techniques and found that top-level overloading significantly affects the stability of slope. Wang et al. [15] analyzed the failure mechanism of a slope by isolating a group of structural planes, and proposed a method to identify the collapsible part of the slope. Chen et al. [1617] applied fracture mechanics and limit equilibrium theory to construct a calculation method with a crag stability coefficient. Tang et al. [18-19] conducted mechanical analysis to explore the evolution process of a groupoccurring collapse disaster of a gently inclining rock stratum with weak base and applied fracture mechanics to develop a method for determining the collapse sequence of rock on a cliff. Zhang et al. [1,4], by taking the Hongyan Cave in Chongqing as an example, analyzed the stability of crags using limit equilibrium and monitoring data, and it was found that the tensile stress of slope and the development depth of rock cell significantly affect the formation and destruction of differentially weathering crags. The above studies have mainly focused on the failure mechanism of hard rock on cliffs and the movement locus and prevention of falling rock after collapse, but the formation mechanism of rock cell has not been fully explained. Rock cell formation leads to the collapse of rock on slope and the weathering of lower soft rock, especially under the joint action of pressure and temperature. Studying the collapse mechanism of rock of gently inclining slope is therefore necessary to establish the weathering mechanism of lower soft rock.

Several studies have conducted on the weathering of rock. Momeni et al. [20] analyzed the strength attenuation law of rock with different weathering degree by employing rock uniaxial compression tests, which then provided basis for the initial obtainment of rock strength according to the weathering degree of onsite rock. Prodam et al. [21] determined the variation rule of mineral composition and changing law of shear strength of siltstones with different weathering degree through field investigation and laboratory tests. Dubois et al. [22] constructed four models based on carbonate samples to estimate rock densities, Poisson's ratios, and calcite dissolutions for different degree of weathering. Their models provide theoretical basis for evaluating the strength of carbonatite. Peng et al. [2], by taking Danxia Cave as an example, conducted field investigations, physical and chemical tests of rock samples, and analytical experiments of water samples to explore the change in mineral composition of rock and weathering of mudstone. They found that the swelling and shrinkage of clay minerals, dissolution of calcareous cements, and hydration of ferruginous cements can lead to rock weathering when mudstone meets underground water. Jiang et al. [5] simulated and analyzed the weathering process of rock by visualizing the constant weakening of cementation between particles through discrete element software programming. The comparative results of simulation and laboratory test showed that the destruction of cementation between particles (i.e., development of microcosmic defects) can lead to the microscopic chemical weathering of rock. Chen et al. [3] applied body slice casting, total analysis of rock, scanning electron microscopy, and other analytical and testing methods to determine the weathering mechanism of carbonatites. Their researches showed that chemical weathering essentially involved the reaction of corrosive groundwater with rock-forming minerals, and this reaction can cause structural damage to the rock. The above studies have mainly analyzed the mineral composition, cement dissolution, and laws of changing strength during rock weathering process, but the mechanical environment of the rock (i.e., pressure produced by upper rock or temperature stress which produced by diurnal temperature difference of atmosphere) has not been fully investigated. Rock under different stress conditions undergoes different weathering mechanism. In other words, different mechanical environment cause different degree damage. Similarly, rock undergoes different weathering rate and peeling of block sizes. The weathering of soft rock beneath gently inclining rock slope is mainly caused by the combined action of pressure and temperature stress of upper hard rock. Therefore, it is necessary to consider the exact mechanical environment of soft rock when explaining the weathering mechanism of gently inclining rock slope.

On the basis of the existing work, the present study first built the calculation method for the damage factor of soft rock beneath gently inclining rock slope by adopting damage mechanics and the heat transfer theory, and considered the joint action of pressure and temperature. Then, the study determined the failure criteria of soft rock according to the fatigue effect of temperature and the accumulation effect of damage. Finally, the study explored the law of weathering and peeling of soft rock under the joint effect of pressure and temperature.

The remaining sections of this study are organized as follows. In the third section, the calculation method of damage mechanics is briefly explained, and the calculation model and fatigue rupture model of the damage factor of soft rock are presented by considering the geologic model of soft rock at the lower part of gently inclining rock slope. In the fourth section, the weathering failure law of mudstone is analyzed, and the mudstone is located in Simianshan Town, Jiangjin District in Chongqing city of China. In the last section, the results of this study are summarized and the relevant conclusions are presented.

\section{Methodology}

\subsection{Calculation method of damage factor}

The method of continuous mechanics is typically adopted in damage mechanics to analyze the characteristics of materials Under the function of external load or environment conditions, the deterioration of structural macro-mechanical properties of materials caused by the initiation and development of microscopic structural defects (e.g., cracks and micro-pores) and other irreversible changes are defined as damage. The weathering of soft rock at the lower part of gently inclining rock slope is essentially a continuous damage of the soft rock under pressure and temperature stress conditions. Subsequently, rock destruction is reached in the final failure mode. The weathering mechanism of soft rock can therefore be explained by damage mechanics, in which the index used to evaluate the material damage is called damage factor. The method for calculating the material damage factor is briefly described in subsequent paragraphs.

Assuming that the strength of soft rock conforms with Weibull distribution, the probability density function [23] can be expressed as: 
$p(\varepsilon)=\frac{m}{\varepsilon_{0}}\left(\frac{\varepsilon}{\varepsilon_{0}}\right)^{m-1} \exp \left[-\left(\frac{\varepsilon}{\varepsilon_{0}}\right)^{m}\right]$

where $\varepsilon$ is the strain of soft rock; $\mathrm{m}$ and $\varepsilon_{0}$ are the scale and morphological function of Weibull distribution, respectively.

According to continuum damage mechanics, the damage factor $D[23]$ is defined as:

$$
D=\int_{0}^{\varepsilon} p(\varepsilon) d \varepsilon
$$

where $D$ is the damage factor, a dimensionless variable.

The boundary condition of formula (2) is:

$$
D=0 \quad(\varepsilon=0)
$$

By integrating formulas (1) and (3) to formula (2), the damage factor $D$ is given as:

$$
D=1-\exp \left[-\left(\frac{\varepsilon}{\varepsilon_{0}}\right)^{m}\right]
$$

The weathering of soft rock beneath gently inclining rock slope is mainly induced by the pressure of upper hard rock and temperature. Fig. 1 presents a typical type of gently inclining slope with rock cell (Fig. 2), in which $\mathrm{H}$ is the height and $B$ is the thickness of the hard rock, and $h$ represents clear height. The depth of the rock cell is $l$. Fig.3 shows the mechanics model of soft rock beneath gently inclining slope. The model indicates that soft rock mainly bear the pressure of hard rock(i.e., pressure $\mathrm{q}$ over resultant force $F$ on the cantilever) and the shear stress of the contact plane between the hard and soft rock.

The uniform load $q$ above the soft rock is:

$q=\gamma H$

where $\gamma$ is the unit weight of hard rock.

The shear stress $\tau$ of the contact plane between the hard and soft rock is:

$\tau=q \tan \phi+c$

where $\varphi$ is the internal friction angle of the contact plane and $C$ is the cohesive strength of the contact surface.

The resultant force $F$ of the cantilever part of the hard rock acting on the soft rock is given as:

$F=\gamma H l$

Under the action of pressure and contact load of the hard rock, the internal force at arbitrary point $M$ of the soft rock can be expressed as:

$$
\sigma_{z}=q+\gamma\left(z+\frac{h}{2}\right)+\frac{2 F}{\pi} \frac{\cos ^{3} \theta}{\rho}
$$

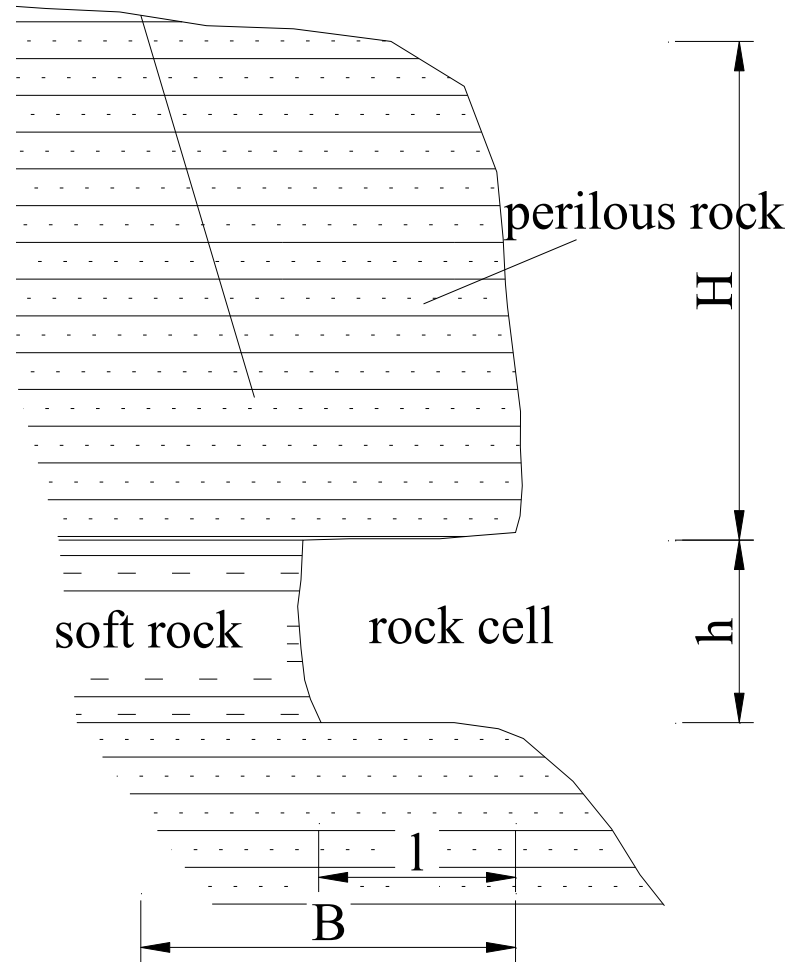

Fig. 1. Perilous rock model of interbedded soft-hard rock

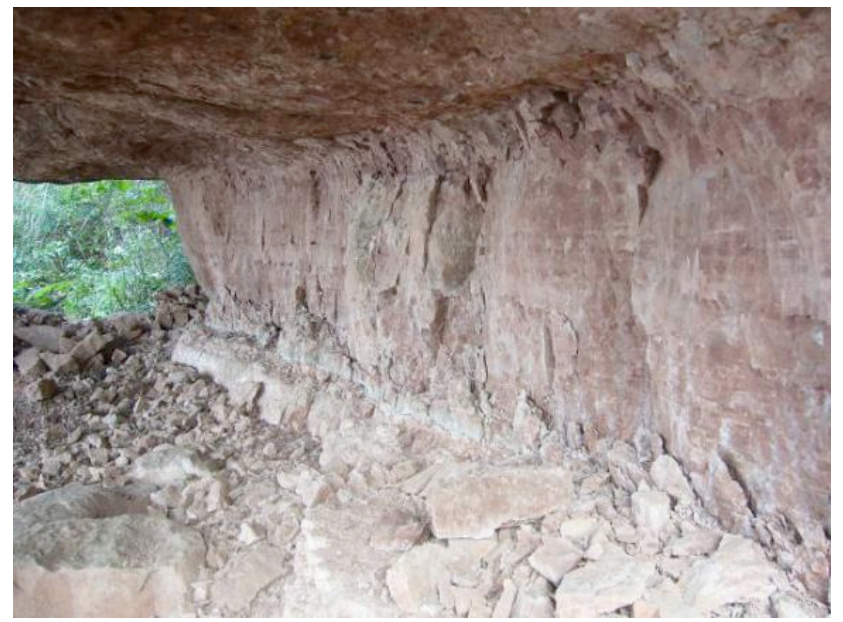

Fig. 2. Rock cell

$\sigma_{x}=\frac{12\lfloor\tau+\gamma(z+h / 2) \tan \rfloor}{h^{2}} x z$

$+\frac{2 F}{\pi} \frac{\sin ^{2} \theta \cos \theta}{\rho}$

$\tau_{x z}=\frac{4[\tau+\gamma(z+h / 2) \tan ]}{3}\left\lfloor 1-\left(\frac{z}{h}\right)^{2}\right\rfloor$

$+\frac{2 F}{\pi} \frac{\sin \theta \operatorname{in} \theta^{2} \theta}{\rho}$

where $\rho$ is the straight distance between point $M$ and the action point of resultant force $F ; \theta$ is the angle between the lines, which include point $M$ and action point $F$ along the vertical direction; $\mathrm{x}$ is the horizontal coordinate; $\sigma_{z}$ is vertical compressive stress; $\sigma_{x}$ is horizontal tensile stress; and $\boldsymbol{\tau}_{x z}$ is shear stress. 
According to Hooke's law, the strain of the soft rock along the $\mathrm{x}$-direction under the action of pressure and contact load of the hard rock is given by:

$\varepsilon_{x 1}=\frac{1-\mu^{2}}{E_{1}}\left(\sigma_{x}-\frac{\mu}{1-\mu} \sigma_{z}\right)$

where $\varepsilon_{x 1}$ is the strain of soft rock along the X-direction; $\mu$ is the Poisson's ratio and $E_{1}$ is the elastic modulus.

The soft rock, which extend toward the mountain interior, can be simply described as a semi-infinite body. Assuming that the atmospheric temperature is $T_{1}$, the temperature of the soft rock within the rock cell is $\mathrm{T}(\mathrm{x}, \mathrm{t})$ (Fig. 4). To simplify the calculation, assuming that the temperature of the soft rock is mainly transferred along the $\mathrm{x}$-direction

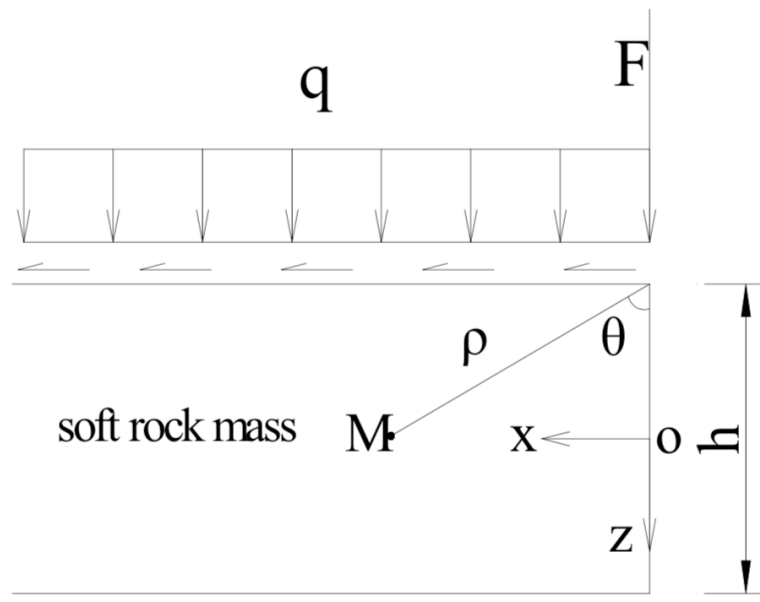

Fig. 3. Mechanics model of soft rock

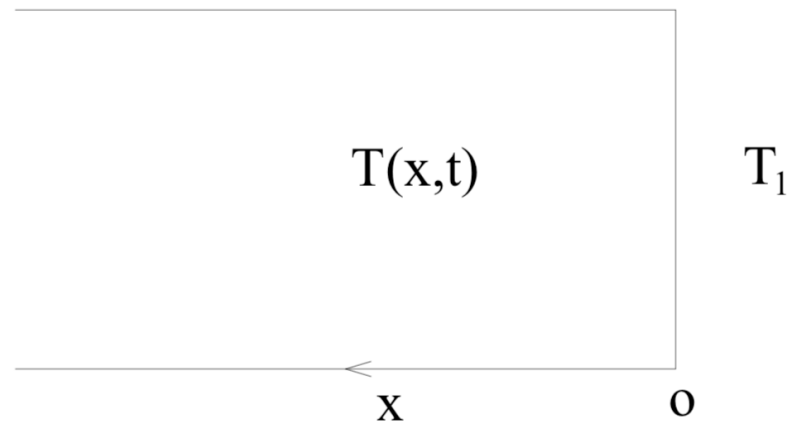

Fig. 4. Temperature distribution map of soft rock

With the transmission of atmospheric and soft rock temperature, the control equation [24] can be expressed as:

$\frac{\partial T(x, t)}{\partial t}=A \frac{\partial^{2} T(x, t)}{\partial x^{2}}$

where $\mathrm{T}(\mathrm{x}, \mathrm{t})$ is the temperature at any time-point of the soft rock in arbitrary place $\mathrm{x} ; t$ is time; and $A$ is thermal diffusivity $\left(\mathrm{m} / \mathrm{s}^{-1}\right)$.

The boundary conditions of formula (12) are given as follows:

$T(x, t)=T_{0} \quad t=0$
$T(x, t)=T_{1} \quad \mathrm{x}=0$

By integrating formulas (13) and (14) to formula (12), it can be expressed as follows:

$\frac{T(x, t)-T_{1}}{T_{0}-T_{1}}=\operatorname{erf}\left(\frac{x}{\sqrt{2 A t}}\right)$

$\operatorname{erf}(x)=\frac{2}{\sqrt{\pi}} \int_{0}^{x} e^{-t^{2}} d t$

where $\operatorname{erf}(\mathrm{x})$ is the error function.

By transforming formula (15), the temperature of point $\mathrm{x}$ at any time-point is given as:

$$
T(x, t)=T_{1}+\left(T_{0}-T_{1}\right) \operatorname{erf}\left(\frac{x}{\sqrt{2 A t}}\right)
$$

Then, the temperature stress caused by temperature transformation can be expressed as:

$\sigma_{T}=\frac{E_{1} \alpha \Delta T}{1-\mu}=\frac{E_{1} \alpha\left[T(x, t)-T_{1}\right]}{1-\mu}$

The strain of the soft rock caused by temperature stress is given as:

$\varepsilon_{T}=\frac{\sigma_{T}}{E_{1}}$

The total strain of the soft rock along the $\mathrm{x}$-direction under the combined action of pressure and temperature is expressed as:

$\varepsilon_{s}=\varepsilon_{T}+\varepsilon_{x}$

Consequently, the failure criteria of soft rock according to limit strain $\varepsilon_{\mathrm{d}}$ is given as:

If $\varepsilon_{\mathrm{s}}<\varepsilon_{\mathrm{d}}$, then the soft rock is not in failure mode.

If $\varepsilon_{\mathrm{s}}=\varepsilon_{\mathrm{d}}$, then the soft rock is in critical state.

If $\varepsilon_{\mathrm{s}}>\varepsilon_{\mathrm{d}}$, then the soft rock is in failure mode.

The effective stress $\tilde{\sigma}$ of the rock mass in relation to the soft rock damage[25] is defined as:

$\tilde{\sigma}=\frac{\sigma}{1-D}$

where $\sigma$ is the stress of the rock mass, which does not take into consideration the damage of the soft rock.

By integrating formula (4) to formula (21), it can be expressed as follow:

$\sigma=\tilde{\sigma} \exp \left[-\left(\frac{\varepsilon}{\varepsilon_{0}}\right)^{m}\right]=E_{1} \operatorname{sexp}\left[-\left(\frac{\varepsilon}{\varepsilon_{0}}\right)^{m}\right]$

The stress-strain curve of the rock under uniaxial compression loading is shown in Fig. 5, in which stress peak point is represented by $\mathrm{c}$, while stress and strain are represented by $\sigma_{c}$ and $\varepsilon_{\mathrm{c}}$, respectively.

A derivation of formula (22) is expressed as: 
Wang Lin-feng, Sun Hao, Yao Chang-yin, Jin Hong-hua, Tang Hong-mei, Wang Zong-jian/

Journal of Engineering Science and Technology Review 11 (1) (2018) 165-173

$\frac{\partial \sigma}{\partial \varepsilon}=E_{1} \exp \left[-\left(\frac{\varepsilon}{\varepsilon_{0}}\right)^{m}\right]$

$-\frac{E_{1} \varepsilon m}{\varepsilon_{0}} \exp \left[-\left(\frac{\varepsilon}{\varepsilon_{0}}\right)^{m}\right]\left(\frac{\varepsilon}{\varepsilon_{0}}\right)^{m-1}$

which reaches the maximum stress at point $\mathrm{c}$. Thus:

$$
\left.\frac{\partial \sigma}{\partial \varepsilon}\right|_{\varepsilon=\varepsilon_{c}}=0
$$

By integrating formula (23) to formula (24), it's transformed into:

$$
\begin{aligned}
& E_{1} \exp \left[-\left(\frac{\varepsilon_{c}}{\varepsilon_{0}}\right)^{m}\right]-\frac{E_{1} \varepsilon_{c} m}{\varepsilon_{0}} \\
& \exp \left[-\left(\frac{\varepsilon_{c}}{\varepsilon_{0}}\right)^{m}\right]\left(\frac{\varepsilon_{c}}{\varepsilon_{0}}\right)^{m-1}=0
\end{aligned}
$$

Then, simplifying formula (25) as:

$$
\left(\frac{\varepsilon_{c}}{\varepsilon_{0}}\right)^{m}=\frac{1}{m}
$$

By integrating the stress and strain values of point $\mathrm{c}$ to formula (22), it can be expressed as:

$$
\sigma_{c}=E_{1} \varepsilon_{c} \exp \left[-\left(\frac{\varepsilon_{c}}{\varepsilon_{0}}\right)^{m}\right]
$$

Then, transforming formula (27) into:

$$
\left(\frac{\varepsilon_{c}}{\varepsilon_{0}}\right)^{m}=-\ln \frac{\sigma_{c}}{E_{1} \varepsilon_{c}}
$$

Combining formulas (26) and (28), the $m$ can be expressed as:

$$
m=-\left(\ln \frac{\sigma_{c}}{E_{1} \varepsilon_{c}}\right)^{-1}
$$

By solving formula (26), the morphological function is given as:

$$
\varepsilon_{0}=m^{l / m} \varepsilon_{c}
$$

At this point, the calculation formula of the Weibull distribution scale and the morphological function of $\mathrm{m}$ and $\varepsilon_{0}$ have been obtained. Subsequently, substituting these parameters into formula (21) to obtain the damage factor of rock under arbitrary loading:

$$
D=1-\exp \left[-\left(\ln \frac{\sigma_{c}}{E_{1} \varepsilon_{c}}\right)^{-1}\left(-\frac{\varepsilon}{\varepsilon_{c}}\right)^{-\left(\ln \frac{\sigma_{c}}{E_{1} \varepsilon_{c}}\right)^{-1}}\right]
$$

The method of calculating the damage factor of soft rock (i.e., see formula (31)) can also be applied to the damage factor under the joint action of upper hard rock and temperature stress. According to the calculation results, the weathering damage of soft rock is determined.

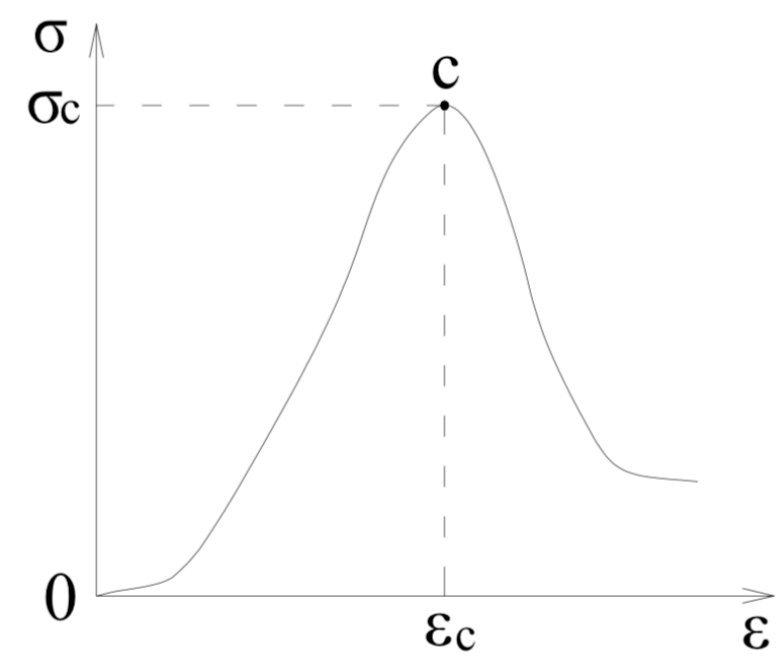

Fig. 5. Stress-strain curve of rock mass

\subsection{Identification of fatigue rupture of soft rock}

The constant alternation of day and night and the related temperature stress induces a kind of alternating load on soft rock. Under the action of this alternating load, soft rock produce fatigue damage. According to damage mechanics, the damage factor after $\mathrm{N}$ times of fatigue action [25] can be expressed as:

$D=1-\left[1-\left(\frac{N}{N_{F}}\right)^{\frac{1}{1-\alpha}}\right]^{\frac{1}{1+\beta}}$

$N_{F}=\frac{1}{(1-\alpha)(1+\beta)}\left(\frac{\sigma_{T}}{M}\right)^{-\beta}$

where $\alpha, \beta$, and M represent the material parameters; $N$ is the number of fatigue damage of soft rock; and ${ }^{\sigma_{T}}$ is temperature stress.

Transforming formula (20), the strain of soft rock undergo $i$ th fatigue action is expressed as:

$\varepsilon_{i}=\varepsilon_{0}\left[-\ln \left(1-D_{i}\right)\right]^{\frac{1}{m}}$

where $\mathrm{D}_{\mathrm{i}}$ is the damage of soft rock during ith fatigue.

On the basis of formulas (32) and (34), the total strain $\varepsilon_{N}$ of soft rock after $\mathrm{N}$ times of fatigue action can be expressed as:

$\varepsilon_{N}=\varepsilon_{0}\left\{-\ln \left[1-\left(\frac{N}{N_{F}}\right)^{\frac{1}{1-\alpha}}\right\}^{\frac{1}{1+\beta}}\right\}^{\frac{1}{m}}$

According to the superposition principle, the total strain $_{\varepsilon_{s}}$ of soft rock caused by the pressure from upper hard rock and fatigue action of temperature is: 
$\varepsilon_{s}=\varepsilon_{x 1}+\varepsilon_{N}$

where $\varepsilon_{x 1}$ is the strain of soft rock caused by the pressure of upper hard rock, while $\varepsilon_{N}$ is the strain of soft rock after $\mathrm{N}$ times of fatigue action under temperature stress.

If $\varepsilon_{s}>\varepsilon_{d}$ ( $\varepsilon_{d}$ is the critical strain in the failure mode of soft rock), then the soft rock begin to collapse and the rock cell retreats. If the condition is the critical state of $\varepsilon_{s}=\varepsilon_{d}$, then formula (36) is used to calculate the times in which soft rock endures the fatigue failure under the combined action of temperature and pressure.

The method of identifying the damage and fatigue rupture of soft rock can be used to determine the weathering and peeling situation of soft rock under the function of temperature fatigue.

\section{Result Analysis and Discussion}

Figs. 6 and 7 present the images of the mudstone beneath a cliff in Hongyan Mountain of Simianshan Town in Jiangjin District. The hard rock above the rock cell is a sandstone. The height of the hard rock is $18 \mathrm{~m}$ and its thickness is 7 $\mathrm{m}$; the length of the controlling structural plane is $9.5 \mathrm{~m}$; the depth of the rock cell is $6 \mathrm{~m}$ and its height is $3 \mathrm{~m}$; and the weight of the sandstone is $25 \mathrm{kN} / \mathrm{m}^{3}$. By contrast, the soft rock is a mudstone. The weight of the mudstone is $23 \mathrm{kN} / \mathrm{m}^{3}$, the elasticity modulus is $2 \times 10^{4} \mathrm{MPa}$; thermal diffusivity is $12 \times 10^{-3} \mathrm{~cm}^{3} / \mathrm{s}$; and the coefficient of the linear expansion is $5 \times 10^{-6} / \mathrm{C}^{-1}$. The material damage parameters of the mudstone are $\alpha=-1.86, \beta=0.72$, and $\mathrm{M}=8.16 \times 10^{6} \mathrm{MPa}$ $[24,26]$. The tensile strength of the mudstone is $5 \mathrm{MPa}$ and its limiting strain is $3 \times 10^{-4}$.

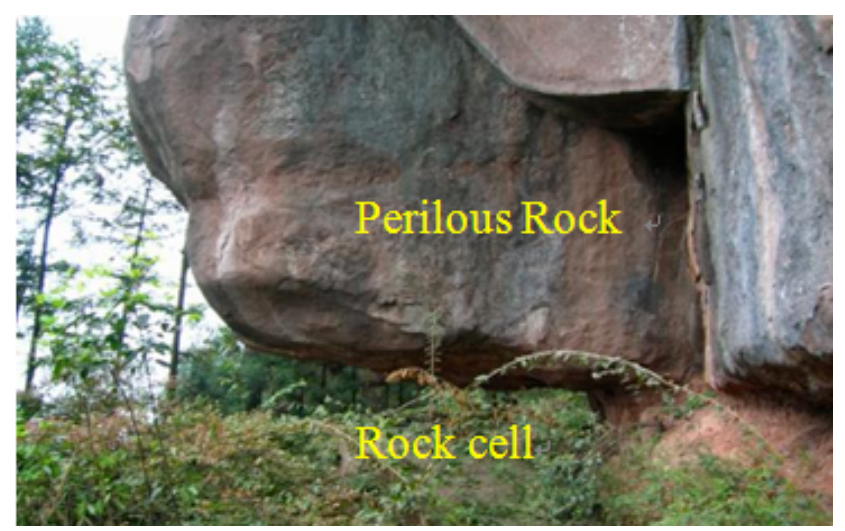

Fig. 6. Hongyan Mountain rock cell

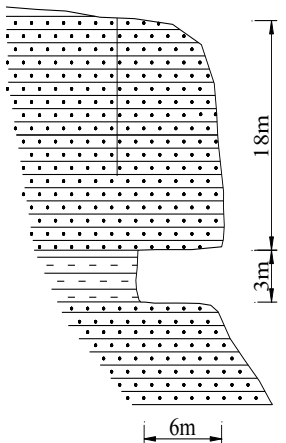

Fig.7. Physics model of the Hongyan Mountain rock cell
The annual average temperature in Simianshan Town is $287.15 \mathrm{~K}$, and this average is designated as the initial temperature of the mudstone. Then, the temperature exchanged on August 28, 2016 is applied to analyze the weathering of soft rock(i.e., the daily average temperature on that day was $301.15 \mathrm{~K}$ ). Finally, the temperature change of the mudstone is calculated according to the temperature field formula in Section 3.1 (Fig. 8 and Table 1).

The surface of the mudstone has the highest temperature, as shown in Fig. 8. Furthermore, the temperature of the mudstone decreases rapidly as depth increases. After 24 hours of temperature exchange, the maximum influencing depth of the external temperature on the mudstone is approximately $1 \mathrm{~m}$. In 2016, Simianshan Town had 185 days with an average temperature higher than the average temperature. The average temperature for those 185 days is $297.15 \mathrm{~K}$ and is considered as the fatigue temperature. Calculations are conducted following the method of identifying the fatigue rupture of soft rock (Section 3.2).The mudstone start to fall after 158 times of temperature loading. Fig. 9 and Table2 show the relationship between the fatigue time and total strain of the mudstone under the fatigue of 297.15 K. As depicted by the curve in Fig. 9, the strain on the mudstone surface notably increases at the start of the loading. However, as the frequency increases, the rising strain on the mudstone surface becomes less apparent (Table 2).

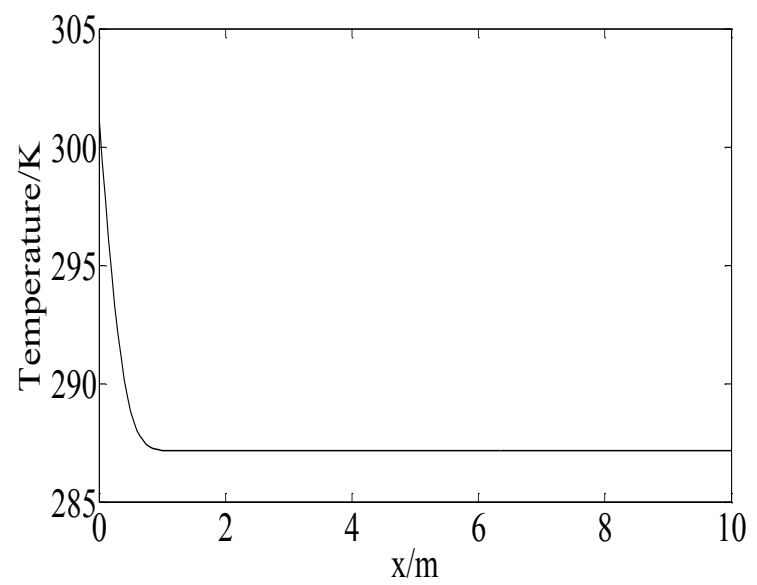

Fig. 8. Temperature variation curve of mudstone along the x-direction

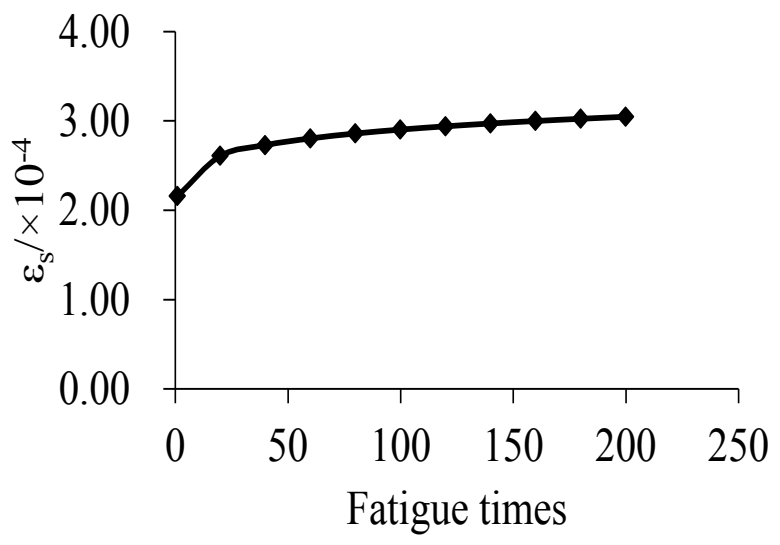

Fig. 9. Total strain versus fatigue times 
Wang Lin-feng, Sun Hao, Yao Chang-yin, Jin Hong-hua, Tang Hong-mei, Wang Zong-jian/

Journal of Engineering Science and Technology Review 11 (1) (2018) 165-173

Table 1. Temperature value of the mudstone along the $\mathrm{x}$-direction

\begin{tabular}{l|lllllllllll}
\hline $\begin{array}{l}\text { Temperature } \\
\mathbf{T} / \mathbf{K}\end{array}$ & 301.15 & 299.42 & 297.74 & 296.13 & 294.63 & 293.28 & 292.07 & 291.03 & 290.15 & 289.42 & 288.84 \\
\hline $\mathbf{x} / \mathbf{m}$ & 0.00 & 0.05 & 0.10 & 0.15 & 0.20 & 0.25 & 0.30 & 0.35 & 0.40 & 0.45 & 0.50 \\
\hline $\begin{array}{l}\text { Temperature } \\
\mathbf{T} / \mathbf{K}\end{array}$ & 288.38 & 288.02 & 287.76 & 287.57 & 287.43 & 287.33 & 287.27 & 287.22 & 287.19 & 287.18 & 287.17 \\
\hline $\mathbf{x} / \mathbf{m}$ & 0.55 & 0.60 & 0.65 & 0.70 & 0.75 & 0.80 & 0.85 & 0.90 & 0.95 & 1.00 & 1.05 \\
\hline $\begin{array}{l}\text { Temperature } \\
\mathbf{T} / \mathbf{K}\end{array}$ & 287.16 & 287.16 & 287.15 & 287.15 & 287.15 & 287.15 & 287.15 & 287.15 & 287.15 & 287.15 & 287.15 \\
\hline $\mathbf{x} / \mathbf{m}$ & 1.10 & 1.15 & 1.20 & 1.25 & 1.30 & 1.35 & 1.40 & 1.45 & 1.50 & 1.55 & 1.60 \\
\hline
\end{tabular}

Table 2. Mudstone stress versus fatigue times

\begin{tabular}{l|c|c|c|c|c|c|c|c|c|c|c|c|c|}
\hline $\begin{array}{l}\text { Fatigue } \\
\text { times/Times }\end{array}$ & $\mathrm{N}$ & 1 & 20 & 40 & 60 & 80 & 100 & 120 & 140 & 160 & 180 & 200 \\
Stress/E-04 & $\mathrm{Es}$ & 2.16 & 2.61 & 2.73 & 2.80 & 2.86 & 2.90 & 2.94 & 2.97 & 3.00 & 3.02 & 3.05 \\
\hline
\end{tabular}

The temperature field formula used to calculate the damage factors (Section 3.1) can also be used to determine the internal temperature distribution of the soft rock with varying temperature difference. Fig. 10 shows the temperature change curve of the soft rock under the different diurnal temperatures of $275.15,279.15,283.15$, and $287.15 \mathrm{~K}$. The temperature of the soft rock surface rapidly decreases as rock depth increases.

Fig. 11 shows the maximum influencing depth of the temperature on soft rock under varying diurnal temperature conditions. Given four different situations, the maximum influencing depth of the rock is approximately $1.00-1.20 \mathrm{~m}$. Therefore, the impact of daily diurnal temperature difference on the rock is limited. In other words, the changes in temperature resulted in weathering depths approximately $1.00-1.20 \mathrm{~m}$, which is in line with the current onsite situation wherein surface rock is crumbly while core rock is relatively unaffected. Furthermore, the curve in Fig. 4 appears nearly flat. The findings imply that the increase in temperature difference only has a minimal effect on the maximum depth of soft rock. The presented parameters are the functions of the active time of temperature and heat transfer property of rock.

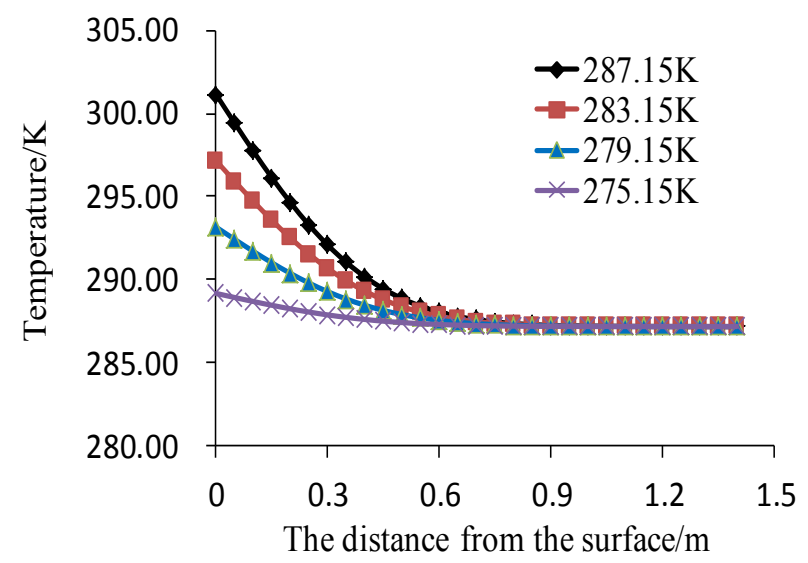

Fig. 10. Temperature change of mudstone along the x-direction under different external temperature conditions

As discussed in section 3.1, the damage factor $D$ of soft rock can be calculated by considering the variations in temperature difference. Fig. 12 shows the changing curve of the damage factor of soft rock under different diurnal temperature conditions. The diurnal temperature difference is in the range of $275.15-299.15 \mathrm{~K}$. The curve of Fig. 12 also implies that rock damage increases as the temperature difference increases. The curve also appears nearly flat, which suggests that the rock damage is sensitive to temperature difference. As diurnal temperature difference increases from 275.15 to $299.15 \mathrm{~K}$, the rock damage reaches $100 \%$. Thus, the larger the diurnal temperature difference is, the faster the weathering rate will be.

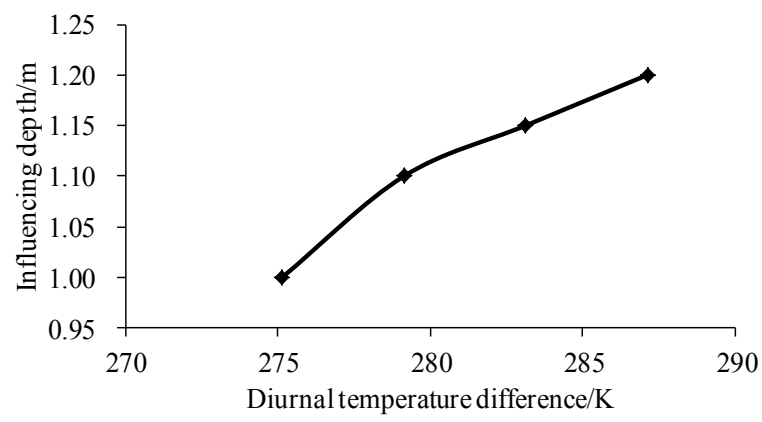

Fig.11. Influencing depth of temperature of mudstone under varying temperature difference conditions

The damage factor of the soft rock caused by varying temperature difference and fatigue number was calculated according to the damage factor formula for the method of identifying temperature fatigue (Section 3.2).

As shown in Fig. 13, the diurnal temperature difference is from 275.15 to $299.15 \mathrm{~K}$. As depicted by the curves, the damage to soft rock is apparent when fatigue number increases. As the temperature fatigue load increases, the rock damage rate increased rapidly. As the fatigue number continue to increases, the rock damage rate also increases, but at a relative slower pace. When the damage exceeds the critical value, the rock start to fall apart, which corresponds to the onset of weathering and peeling of soft rock. Fig. 13 also shows that when the diurnal temperature difference is relatively small, the distances between the curves are relatively wide. The finding indicates that when the temperature difference is relatively low even as temperature increases, the rock undergoes serious damage, i.e., weathering rate increases. By contrast, when the external temperature difference of the soft rock is relatively high, any increase in the temperature difference results in an insignificant increase in rock damage, i.e., weathering rate increases at a lower level. 


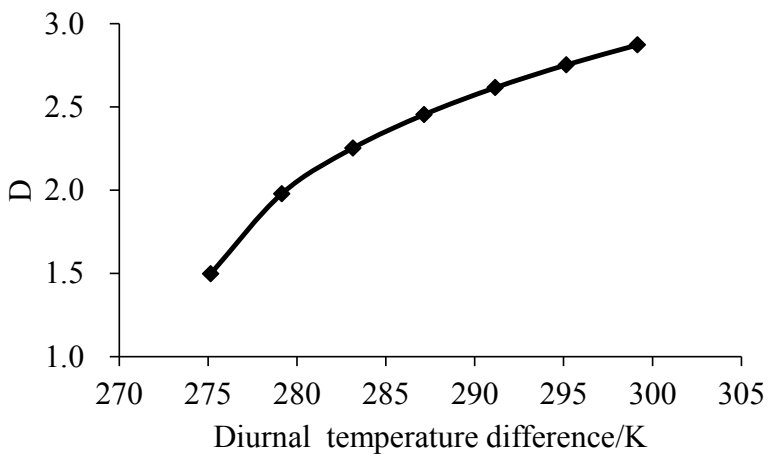

Fig. 12. Damage factor $D$ caused by variations in temperature difference

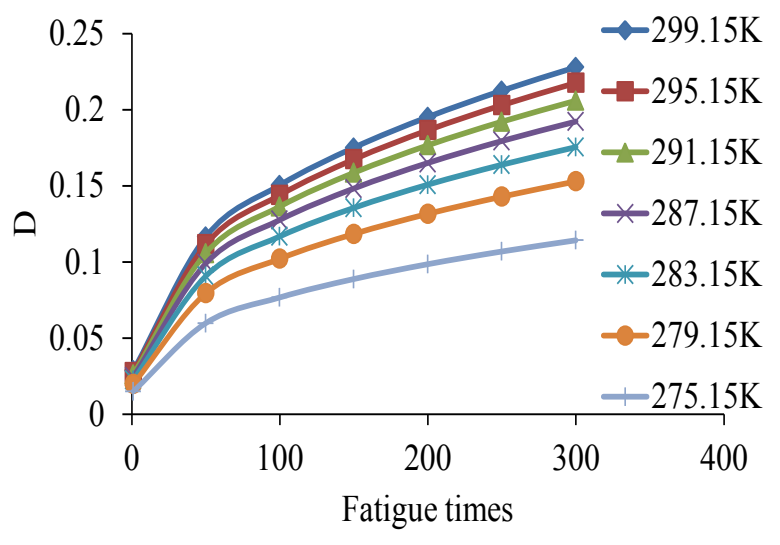

Fig. 13. Fatigue times versus damage factor $D$ under varying temperature difference conditions

Fig. 14 shows the damage to soft rock under the different stress conditions of upper hard rock. As depicted by the figure, the rock damage increases gradually as stress (q) increases. The increase in pressure at the upper part of the rock mass can accelerate the weathering rate of soft rock. Thus, on the basis of point distribution, a linear relationship exists between upper hard rock stress and soft rock damage. Subsequently, the formula can be derived by fitting the damage factor with the press stress of upper hard rock:

$D=0.0003 q+0.0226$

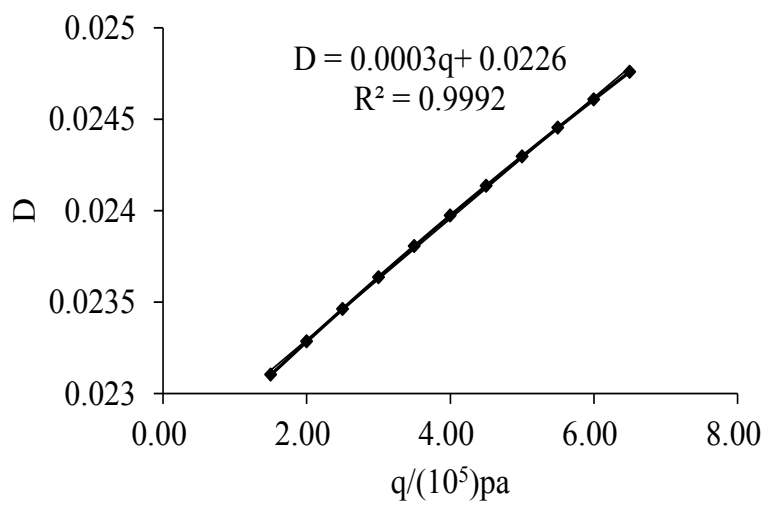

Fig.14. Damage factors $D$ under various pressure conditions

\section{Conclusion}

The method for determining the weathering mechanism of soft rock at the lower part of gently inclining rock slope has been established in the study. Then, the formula of the damage factor and the method to identify the fatigue rupture of soft rock under the combined action of hard rock pressure and temperature stress were proposed. The following conclusions can be drawn:

(1) On the basis of the internal distribution law of soft rock under varying diurnal temperature difference conditions, the maximum weathering depth of soft rock caused by temperature changes is $1.00-1.20 \mathrm{~m}$. The values are in line with the current onsite situation wherein surface rock is crumbly and core rock is relatively unaffected.

(2) On the basis of the change law for the damage factor of soft rock under varying diurnal temperatures, the weathering of soft rock is sensitive to temperature difference. When the diurnal temperature difference increases from 275.15 to $299.15 \mathrm{~K}$, the weathering rate of the rock increased by $100 \%$.

(3) As the fatigue number increases, the damage of the soft rock increases. At the beginning of the loading process, the weathering rate is high, however, as the fatigue number increases, the weathering rate slows down gradually.

(4) When the temperature difference is low, as the temperature increases, the weathering rate of the soft rock increases. While the temperature difference is large, the temperature has a little influence on the weathering rate of the soft rock.

(5) The pressure of hard rock at the top part of the rock mass is linearly related to the damage of the soft rock. As the pressure at the top part of the rock mass increases, the weathering rate of soft rock increases.

The formula, method, and analytical approaches for soft rock proposed in this study provide a theoretical foundation for the prevention and treatment of near-collapse or postcollapse segments of gently inclining rock slope, which are generally known to easily lead to disasters.

The above methods considered the weathering of soft rock at the two-dimensional level only. However, the weathering of soft rock is essentially a three-dimensional problem. Thus, subsequent researches may focus on the three-dimensional stress condition of soft rock and the threedimensional transmission of temperature. The result from further research may help explain the weathering mechanism of soft rock with higher accuracy.

\section{Acknowledgements}

The study was financially supported by the National Natural Science Foundation (51408084, 51378521, and 51678097), Science and Technology Project affiliated with the Education Department of Chongqing Municipality (KJ1400317) in 2014, the Foundation of Chongqing Jiaotong University (2013kjc043), and National Key Research and Development Plan Project (2016YFC0802203).

This is an Open Access article distributed under the terms of the Creative Commons Attribution Licence 


\section{References}

1. Zhang, Y. X., Lu, L., Zhang, S. P., "Development and failure principle of differential weathering over hanging rock". Journal of Civil Architectural \& Environmental Engineering, 32(32), 2010, pp.1-6.

2. Peng, H., Qiu Z. W., Pan Z.X., "Experimental study on the weathering features of bedding cavesat Mt.Danxiashan". Earth Science, 34(4), 2014, pp.454-463.

3. Chen, J. P., Xu, Z. M., "Study on chemical weathering mechanisms of a roadbed slope".Hydrogeology \& Engineering Geology, 41(6), 2014, pp.134-140.

4. Chen, W., Xu, Z. M., Liu, W. L., "Mechanical model and failure mechanism of unstable cantilevered rock blocks due to differential weathering". Rock and Soil Mechanics, 36(1), 2015, pp.195-203.

5. Jiang, M. J., Zhang, N., Chen, H., "Discrete element simulation of aging effect of chemical weathering on rock". Rock and Soil Mechanics, 35(12), 2014, pp.3577-3584.

6. Zhang, H. M., Peng, C., Yang, G. S., "Study of damage statistical strength criterion of rock considering the effect of freezing and thawing". Journal of China University of Mining \& Technology, 46 (5), 2017, pp.1067-1062.

7. Werner, R., Michael, B., Herwig, R., "Evaluating the effects of forest management on rockfall protection and timber production at Slope scale". Scandinavian Journal of Forest Research, 38(8), 2015, pp.719 - 731 .

8. Lee, S. G., Hencher, S. R., "Assessing the stability of a geologically complex slope where strong dykes locally act as reinforcement ".Rock Mechanics and Rock Engineering, 46 (10), 2013, pp.1339-1351.

9. Ke, Z., Ping, C., Jing, J. M., "Modeling the progressive failure of jointed rock slope using fracture mechanics and the strength reduction

method ". Rock Mechanics and Rock Engineering, 47(4), 2014, pp.115 .

10. Xu , N. W., Dai, F., Liang ,Z. Z., "The dynamic evaluation of rock slope stability considering the effects of microseismic damage". Rock Mechanics and Rock Engineering, 47(4), 2014, pp.621-642.

11. Ali, M. A. Abd-Allah., E. K. El-Sawy., El-SayedSedek. Abu. Seif., "Rock slope stability and design in Arafat-Muzdalifaarea, SaudiArabia ". Arabian Journal of Geosciences, 15(8), 2013, pp.114.

12. Doug, S., Andrea, W., "A critical review of rock slope failure mechanisms: The importance of structural geology". Journal of Structural Geology, 74 (1), 2015, pp.1-23.

13. Rasin, D., "Slope stability with permanent rock anchors". Advances in Analysis, Modeling \& Design, 37(1), 2010, pp.273-282.
14. Shukla, S. K., Khandelwal, S., Verma, V. N., "Effect of surcharge on the stability of anchored rock slope with water filled tension crack under seismic loading condition". Geotechnical and Geological Engineering, 27(4), 2009, pp.529-538.

15. Wang, L. F., Chen, H. K., Tang, H. M. "Mechanical mechanism of failure for anti-inclined rock slopes". Chinese Journal of Geotechnical Engineering, 35(5), 2013, pp.884-889.

16. Chen, H. K., Xian, X. F., Tang, H. M. "Stability analysis method for perilous rock by fracture mechanics". Journal of Chongqing University, 32(4), 2009, pp.434 -437.

17. Chen, P. Y., Zeng, H. B., Shi, H. P., "Stability evaluation of unstable rock based on particle flow simulation and fracture mechanics". Journal of Natural Disasters, 25(3), 2016, pp.87-95.

18. Tang, H. M., Wang, L. F., Chen, H. K., "Collapse sequence of perilous rock on cliffs with soft foundation".Chinese Journal of Geotechnical Engineering,32 (2), 2010, pp.205-210.

19. Wang, L. F., Chen, H. K., Tang, H. M., "Optimization approach for perilous rock reliability analysis based on fracture mechanics". China Journal of Highway and Transport, 26(1), 2013, pp.51-57.

20. Momeni , A., Hashemi , S. S., Khanlari, G. R., "The effect of weathering on durability and deformability properties of granitoid rocks". Bulletin of Engineering Geology and the Environment, (76) 2017, pp.1037-1049.

21. Martina, V. P., Marta, M., Snježana, M. A., "The influence of weathering processes on the shear strength of siltstones from a flysch rock mass along the northern Adriatic coast of Croatia" Bulletin of Engineering Geology and the Environment, (76), 2017, pp.695-711.

22. Caroline, D., John, D., Olivier, K., "A new method to quantify carbonate rock weathering”. Mathematical Geosciences, (47), 2015, pp.889-935.

23. Zuo, J. P., Zhou, H. W., Xie, H. P., "Fracture characteristics of sandstone under thermal effects". Engineering Mechanics,25(5), 2008, pp.124-130.

24. Yang, S. M., Tao, W. Q., 2011.Heat transfer. China Higher Education Press, Beijing, China, pp.124-130.

25. Rashid, K., Abu, A., Sun, M. K., "Computational applications of a coupled plasticity-damage constitutive model for simulating plain concrete fracture". Engineering Fracture Mechanics, (77), 2010, pp.1577-1603.

26. Dattoma, V., Giancane, S., Nobile , R., "Fatigue life prediction under variable loading based on a new non-linear continuum damage mechanics model". International Journal of Fatigue, (28), 2006, pp.89-95. 